\title{
Preliminary interviews: diagnoses and comorbidities
}

\begin{abstract}
The aim of this piece is to report a case originally described as a book chapter, in Portuguese, in "APOIAR: Novas Propostas em Psicologia Clínica" organized by Tardivo \& Gil ${ }^{1}$ edited by Sarvier in São Paulo, Brazil. From the psychoanalytical perspective, the initial interviews serve the following four purposes: symptom function, diagnostic function, transferential function and subjective rectification. The case reports the process of the initial interviews to set the diagnoses and course of work for short-term therapy of a young woman who sought our services at the Psychology Institute - University of São Paulo, Brazil, that year. It presents the process according to a psychoanalytical point of view and the dilemmas encountered. One will be able to see how the analyst's interventions in this case was crucial to bring about each function and to set the right course of treatment. We will also be able to explore the difficulties to close a diagnose and considerations on possible comorbidities will be made.
\end{abstract}

Keywords: preliminary interview, diagnose, psychoanalyses, comorbidities, neuroses
Volume 2 Issue 6 - 2018

\section{Erika Ferreira de Azevedo}

Psychologist, University of São Paulo, São Paulo, Brazil

Correspondence: Erika Ferreira de Azevedo, Psychologist from the University of São Paulo, Learning Support Teacher at St. Paul's School, Rua Tiagem, 25I, apt. 24, CEP:05334-050, São Paulo, São Paulo, Brazil,Tel (55 II) 9 6239-1677, Email erikazavedo@gmail.com

Received: November 14, 2017 | Published: December 06, 2018

\section{Case report}

Quinet ${ }^{2}$ citing Freud, has said, "the first goal of the analyses is to connect the patient to the treatment and to the analyst" (p.13) and "to establish the diagnoses" (p.14). This initial contact is crucial for the patient to open up to the treatment. At the same time, for psychoanalysis, this initial contact is also paramount to observe the types of transferences established (or not) between patient and analyst in order for a diagnoses hypotheses to be created (whether it is neuroses, psychoses or perversion and in the case of neuroses, hysteria or obsession) which will then lead the treatment.

Through a case study of patient from APOAIR ${ }^{1}$ this article will describe the four moments of the initial (or preliminary) interview as described by Quinet ${ }^{3}$ and its four functions: symptom function, diagnostic function, transferential function and subjective rectification. We will also present the dilemmas encountered and the considerations on comorbidities we were able to make.

Agatha $^{2}$ had five initial interviews before the treatment of shortterm therapy began. The first important function we can observe here is the symptom. It is the job of the analyst to question the symptom and direct it to him or herself in the form of a question. It is interesting to see how Agatha called the service with one problem - having gained weight, panic attacks, feeling of detachment - and how during the first interview it already changed to the deep guilt she felt for having cheated on her husband. During the initial interviews, Agatha focused on the others their wrong doings and an intervention, in order to transform her symptom, from my part, was difficult. The shift came in the last interview when I said to her "I hear you, but what are you trying to tell me with that?" instead of just asking her what that meant This way I acted, as Lacan ${ }^{3}$ states, I completed the symptom "with this symptom, the individual directs herself to the analyst with a question - what does that mean? This position includes the knowing because it supposes the analyst to know the truth about her symptom" (p.18). At this moment, Agatha could verbalize, "I'm anxious and intolerant, why?".

${ }^{1}$ A free psychotherapy service offered at the Psychology Institute of the University of São Paulo, Brazil.

${ }^{2}$ Fictitious name.
This symptom transformation is only possible when the patient connects with the analyst. When there is transference. This means the patience is depositing on the analyst the power to know. Agatha expresses that when she says "I know it's wrong, I know I can be annoying with people, but I can't help it and I'd like to know why I am like that". Addressing this matter to me, Agatha is establishing transference, which is, of course, a function of the patient that the analyst manages. For a while during the initial interviews, we were paralyzed in the dilemma around the fact that the patient cheated on her husband. Her annoyance was not with the cheating itself but the fact that she had failed, that she had been imperfect and done something wrong even if she actually thought her husband deserved it. When the patient is able, earlier, to generalize the way she is "I'm annoying and intolerant", she is able to present herself to me in personal terms; it is my cue - through this transference moment - to work on her real symptom, that is: by not accepting the imperfections of others ("annoying and intolerant"), she is actually hiding her difficulty to accept her own mistakes.

As far as the diagnostic function, psychoanalysis presents three clinical structures: neuroses, psychoses and perversion; within neuroses, we consider two clinical types: hysteria and obsessive compulsive. That is when we start encountering barriers and obstacles. Citing Hegenberg et al. ${ }^{4}$ warns us, "as social issues have changed, so has the psychological configuration of the unconscious, whose clinical result is the increase of borderline cases" (p.16). Superficially it was not difficulty to classify Agatha as hysteria especially due to discourses such as "everyone knows I am not wrong" where she positioned herself as a martyr of her stories. However, her habit of verbal diarrhea was question in supervision group where her subjective boundaries were put to question. Where were day? The patient also displayed important impulsive behaviour in her reactions to others and binge eating which could easily classify her as borderline according to Hegenberg's description. In the end, we chose to follow the treatment considering her having as a neurotic structure with a hysteric clinical type. However, these comorbidities are important to mention to place this diagnoses in the social-historic moment we are living in.

Despite some primitive defense mechanisms, the central issue for 
Agatha's differential diagnoses was her relation to the object, to the others. In one of the interviews, Agatha revealed her dissatisfaction with her husband despite what he did, whether it was something she wanted or not. She said, "I too did not want to have sexual intercourse with him, I was also tired with the problems we were having with our store in my mind, but I wanted him to have looked for me". Besides showing coherent cognitive logic in this discourse, Agatha also shows us the biggest issue for the hysteric, which is putting the other in the position of never being good enough. According to Quinet "to the Other [...] she owes nothing: it is the Other who owes it to her" (p.24).

In Agatha's case, as already mentioned, her predominant structure is the neurotic one and her clinical type is the hysteria. It is important to stress how the process of these preliminary interviews allowed for this to be configured. Without the proper management from the analyst, the initial interview functions - diagnostic, symptomatic, and transferential - would have happened as described. Further, it was all only possible because of a fourth function of the preliminary interviews, the subjective rectification which allows the patient to take responsibility and ownership over her own neurosis. This can only happen in the neurotic structure. At the moment Ataha is able to say "I am annoying, I can't control myself", she is moving towards implicating herself in her story, "in her request of the Other, moving from the position of sacrificed victim to the position of the agent, of the actor of the intrigues which she is complaining about and which sustains her desire in the dissatisfaction". ${ }^{2}$
Finally, we were able to see Agatha as an actor of her individual processes but also as a result of the modern society. For this reason, during these initial interviews, we had to be attentive to other symptoms and processes and constituted themselves as potential comorbidities and which deserved care. This reminds us that, despite any diagnose, an individual is his or her own history inserted in a time, a place and living an individual's story.

\section{Acknowledgments}

None.

\section{Conflicts of interest}

The author declares there is no conflicts of interest.

\section{References}

1. Tardivo LSLPC, Gil CA. SUPPORT: New Proposals in Clinical Psychology. Sarvier; 2008.

2. Quinet A. As 4 + Condições de Análise. Sarvier; 1991.

3. Quinet A. Uncovered from the Unconscious: from desire to symptom. Sarvier; 2000.

4. Hegenberg M. Borderline. Casa do Psicólogo. 2000. 